\title{
Erratum to: On optimal designs for censored data
}

\author{
Dennis Schmidt • Rainer Schwabe
}

Published online: 9 August 2014

(C) Springer-Verlag Berlin Heidelberg 2014

\section{Erratum to: Metrika \\ DOI 10.1007/s00184-014-0500-1}

In the original publication, Theorem 3.5 was incorrectly published as:

Theorem 3.5 Let $\mathscr{X}=\left\{x_{1}, x_{2}, x_{3}\right\}$ be the design region. For $i, j \in\{1,2,3\}, i \neq j$, let $d_{i j}=Q\left(\beta_{0}+\beta_{1} x_{i}\right)$ and $l \in\{1,2,3\} \backslash\{i, j\}$.

The correct theorem should read as:

Theorem 3.5 Let $\mathscr{X}=\left\{x_{1}, x_{2}, x_{3}\right\}$ be the design region. For $i, j \in\{1,2,3\}, i \neq j$, let $d_{i j}=Q\left(\beta_{0}+\beta_{1} x_{i}\right) Q\left(\beta_{0}+\beta_{1} x_{j}\right)\left(x_{j}-x_{i}\right)^{2}$ and $l \in\{1,2,3\} \backslash\{i, j\}$.

Unfortunately, this error was not noticed during the subsequent stages of publication. The publisher regrets for this mistake.

The online version of the original article can be found under doi:10.1007/s00184-014-0500-1.

\section{Schmidt $(\bowtie) \cdot$ R. Schwabe}

Institut für Mathematische Stochastik, Otto-von-Guericke-Universität Magdeburg,

PF 4120, 39016 Magdeburg, Germany

e-mail: dennis.schmidt@st.ovgu.de

R. Schwabe

e-mail: rainer.schwabe@ovgu.de 